\title{
Acceptance of Swedish e-health services
}

This article was published in the following Dove Press journal:

Journal of Multidisciplinary Healthcare

15 November 2010

Number of times this article has been viewed

\section{Mary-Louise Jung' \\ Karla Loria'}

'Division of Industrial Marketing, e-Commerce and Logistics, Lulea University of Technology, Sweden
Correspondence: Karla Loria

Division of Industrial Marketing,

e-Commerce and Logistics, Lulea

University of Technology, SE-97 I87, Lulea,

Sweden

Email karla.loria@Itu.se
Objective: To investigate older people's acceptance of e-health services, in order to identify determinants of, and barriers to, their intention to use e-health.

Method: Based on one of the best-established models of technology acceptance, Technology Acceptance Model (TAM), in-depth exploratory interviews with twelve individuals over 45 years of age and of varying backgrounds are conducted.

Results: This investigation could find support for the importance of usefulness and perceived ease of use of the e-health service offered as the main determinants of people's intention to use the service. Additional factors critical to the acceptance of e-health are identified, such as the importance of the compatibility of the services with citizens' needs and trust in the service provider. Most interviewees expressed positive attitudes towards using e-health and find these services useful, convenient, and easy to use.

Conclusion: E-health services are perceived as a good complement to traditional health care service delivery, even among older people. These people, however, need to become aware of the e-health alternatives that are offered to them and the benefits they provide.

Keywords: health services, elderly, technology, Internet, TAM, patient acceptance, health-seeking behavior

\section{Introduction}

The percentage of elderly people in the total population is growing steadily, leading to an aging of society that places the public sector under enormous pressure. ${ }^{1}$ As the elderly are the largest consumers of health care, health care costs are soaring while financial resources remain limited. Moreover, the birth rate is decreasing, so fewer people are paying in to public health care. A smaller productive workforce poses an additional threat to health care organizations as it becomes more difficult to recruit qualified staff., ${ }^{2,3}$ A shortage of doctors, nurses, and formal caretakers is expected in the coming ten years. ${ }^{4}$ This is a serious problem, particularly in geographically dispersed countries such as Sweden, as it is crucial to provide access to health care to all citizens - including those living in remote areas, where it often is particularly hard to obtain specialized care. ${ }^{2}$ With health care costs being the fastest-growing government expenditure, there is an enormous pressure on public health to become more cost efficient and effective. . $^{2,5,6}$

E-health, defined as the use of emerging information and communication technology (ICT) and especially the Internet to improve or enable health and health care, has gained an increasing amount of attention. ${ }^{7}$ E-health promises to improve access to health care, 
support information exchange, increase revenue, reduce costs, and improve the quality of patient care..$^{8-10}$

The Internet offers tremendous opportunities, particularly for offering and improving consumer information services with regard to health care. The Internet enables providers to deliver more citizen-centered care faster, and more efficiently. ${ }^{8,10,11}$ Due to its reach, the Internet has the potential to provide globally-oriented information, as well as locally targeted materials, health-related information, and health care services, which result in a huge opportunity for health care improvement overall. ${ }^{11}$ Its interactivity and the vast amount of information available empower citizens to take better care of themselves and to communicate with their doctors. It also provides access to a "virtually worldwide" community. ${ }^{12-14}$ This shift in power has encouraged health care providers to use the Internet to offer new types of health care services. ${ }^{14}$

Yet, even though the potential of the Internet to enhance health care has been acknowledged in practice as well as in academia, its application has proven difficult. ${ }^{15}$ Although health care is the largest service industry, it still lags behind when it comes to leveraging information and communication technology. ${ }^{16-21}$ Organizations can spend substantial amounts of money on information technology (IT) projects that eventually fail. This can happen when services do not correspond to the needs of their users. ${ }^{22}$ In order to understand what services citizens value and how best to provide those services, ${ }^{23}$ this paper investigates the factors determining citizens' acceptance and adoption of e-health services.

The remainder of this paper is structured as follows. In the next section, leading models on technology acceptance and previous work on the acceptance and adoption of e-health are discussed, building the conceptual foundation for the study. Based on the literature review, the objectives of this research are outlined and the methodological approach is described and discussed. This is followed by the results and discussion. Finally, the conclusions are presented, avenues for future research outlined, and the limitations of the study discussed.

\section{Technology acceptance}

Several theories have been developed with the intention of explaining and predicting the use of IT. Among them, the TAM developed by Fred Davis ${ }^{24}$ in 1986 has garnered considerable support. It has been widely examined, validated, and replicated, ${ }^{25-28}$ and has become a "robust, powerful, and parsimonious model for predicting user acceptance."28 The TAM has its roots in the Theory of Reasoned Action (TRA) which was formulated by Fishbein and Ajzen ${ }^{29}$ in
1975. TRA is based on the premise that intention is the main determinant and predictor of a person's actions or behavior. TRA suggests that two constructs influence a person's behavioral intention: attitude toward a behavior and subjective norm or social pressure to carry out or refrain from the behavior. The TRA was designed to explain human behavior in a wide variety of contexts. ${ }^{26}$

Davis $^{26}$ used TRA as his paradigm to develop a model that could specifically explain and predict "user acceptance of computer based information systems." The TAM adapted TRA by replacing several of its measures with two key constructs: perceived usefulness (PU) and perceived ease of use (PEOU). According to Davis ${ }^{30}$ PU is defined as "the degree to which a person believes that using a particular system would enhance his or her job performance." PU is expected to be influenced by perceived PEOU, "the easier a technology is to use, the more useful it can be." 28 PEOU is "the degree to which a person believes that using a particular system would be free of effort." ${ }^{30}$ PEOU is a process of expectancy; PU is an outcome of expectancy. ${ }^{31}$

TAM's dependent variable is actual usage. The model illustrates how the key constructs (PU and PEOU) mediate external variables, affect a person's attitude, and determine the intention of an individual to accept and use a specific technology. The model does not include subjective norm as suggested in TRA. Still, TAM does explain variance in intention better than TRA. ${ }^{26}$

Many studies have tested the validity of TAM and some have extended the model to address different contexts and populations, include constructs like those related to social influence, and extend its explanatory and predictive power. ${ }^{25-28,31-33}$ According to Adams, ${ }^{25}$ TAM can be useful in many settings. It can be employed to obtain feedback on features or design approaches, to diagnose problems of acceptance, or to select software applications. In research it can be used to identify factors influencing success of information systems (IS), IT diffusion, and determinants of adoption.

Yet only a limited number of studies have addressed TAM in the area of health care; most of them have been written from the perspective of health care professionals and physicians. ${ }^{19,34}$ Two studies have investigated individual's acceptance of e-health services. ${ }^{22,33}$ In line with previous IS research, these studies found that perceptions of usefulness are the strongest determinant of acceptance. However, the usability of the services investigated was far less important. 


\section{Research objectives}

Even though those two studies could establish that TAM and other models from IS are useful for predicting e-health acceptance, because of the qualitative and descriptive nature of the papers, it could not be established as to why services are not widely accepted. Being able to demonstrate that the perceived usefulness of a service is the key to an individual's acceptance is only the first step. It is crucial to understand what constitutes usefulness and in what situations services might still not be used even though they are considered useful. Therefore, more in-depth, detailed, and qualitative data is needed. Furthermore, previous research on e-health acceptance used samples that consisted of individuals that had already used a particular e-health service and collected data via online surveys. While this does give insights into the extent to which services are used, it leaves out people who were not yet involved with e-health. We believe that this poses a bias in the sample and a major limitation. For this reason, this paper qualitatively investigates general opinions and expectations of individuals, regardless of their previous use of online services. We believe that this paper contributes to the knowledge that is needed to develop future services that match the needs and wants of citizens and patients. This investigation is exploratory in nature but builds on previous research and takes the assumptions of TAM as its theoretical guideline.

The research objective is then stated as follows: to investigate older people's acceptance of e-health services in order to identify determinants of and barriers to their intention to use e-health.

\section{Method}

The context of this study is the primary health care system in Sweden. Primary health care covers basic health care needs and services and thus offers multiple services. Furthermore, primary health care including patient education, prevention, diagnosis, treatment, and follow-up is the area in which the Internet has the most value as a health care tool for its users. Sweden is a typical European country and the Scandinavian countries in general are known for their very high Internet coverage. This study examines three services offered by Swedish public health care providers: an online health guide, an ask-the-doctor online service, and e-prescriptions. The website of the county council of Norrbotten (www.nll.se), which is rather representative of public health provider's online offerings, serves as an example to relate to during investigation.
The approach taken in this paper is qualitative. The nature of the problem that is to be investigated, factors determining the acceptance and use of e-health services, is an area in which the use of the Internet has made few inroads and requires ethnographic data to be able to understand how individuals form decisions and act. A qualitative design is holistic and enables the investigation of the larger picture that is needed to build up a general understanding in a given social setting. ${ }^{35}$ As highlighted earlier, the purpose of this paper is to explore and describe, not to explain and generalize.

To obtain detailed, qualitative information, in-depth semi-structured interviews were conducted with twelve residents of the county of Norrbotten during the spring of 2007. In-depth interviews were chosen because, according to Yin, ${ }^{36}$ the inclusion of multiple cases increases the external validity of qualitative research. As eight cases is often a sufficient number in qualitative studies, ${ }^{37}$ twelve cases would provide a big enough variation in the age, gender, and background of the members of the sample; we believed that this would be beneficial when exploring user behavior. At the same time, the number of cases is still small enough to be able to examine each case in depth. Finally, after twelve interviewees, a certain level of repetition was reached and the researchers believed that further interviews would not have contributed any additional knowledge. The selection of cases was purposive sampling of critical cases in order to reach the desired level of variance. The intention was to study the biggest consumers of health care, which are, due to the deterioration of health with age, members of the older generations. Two age groups were selected: a younger age group (45 to 64 years of age) and an older age group (65 years of age and older). Six of the respondents were men and six were women.

Each interview lasted an average of one hour and was held at the researchers' site. If the interviewee was more comfortable at home, the interview was conducted there. The interviews were semi-structured, meaning that an interview guide was developed to make sure that no questions were omitted. Yet in keeping with the exploratory nature of the interviews, questions were kept as open as possible.

The purpose of the project and the reason for the interview were explained to the interviewees beforehand. They were asked about their awareness, knowledge, and previous use of e-health services. The three services were briefly described and explained. Using TAM as a conceptual guideline for data collection and as a general coding scheme, the respondents were interviewed about their attitude and feelings toward each of the services, the degree of usefulness and easiness of 
use they would expect, and about any concerns and thoughts they would have. Samples of the services on the county council of Norrbotten (NLL) website were then shown, to find out whether they elicited other issues or ideas, and to encourage the interviewee to assess the ease or difficulty of using the services. Furthermore, the interviewees were asked whether they could see themselves using each of the services, why they would or would not, and about their intention to use such services in the future.

The researchers took turns conducting the interviews. One researcher would hold the conversation while the other took notes and occasionally asked for missing information or clarification. The interviews were tape-recorded (with the interviewee's permission) and transcribed. Based on the transcriptions, case reports were written for each interview and reviewed by both researchers. Following suggestions for the analysis of qualitative data by Miles and Huberman, ${ }^{38}$ data was analyzed within and across cases.

\section{Results}

Six men and six women of differing ages, education, and backgrounds were interviewed for an hour on their knowledge of, opinion and attitude toward, and expectations of e-health services. Table 1 provides an overview of the respondents and their occupation, Internet experience, and knowledge and previous use of e-health. Pseudonyms where used in order to protect the interviewees' identities.

As outlined in Table 1 the respondents vary in their previous use of computers and the Internet, and in their knowledge and use of e-health. Members of the younger age group reported medium to considerable experience with computers and the Internet, mainly because most of them used computers in their jobs. With the exception of Carl, the pastor, who was familiar with the Internet but did not use it frequently, all had some awareness of e-health services and their possibilities. Most had searched for health information online and used the Internet occasionally.

Table I Characteristics of the twelve individuals

\begin{tabular}{|c|c|c|c|c|}
\hline Age group & Name & Occupation & Internet experience & $\begin{array}{l}\text { Previous knowledge } \\
\text { and use of e-health }\end{array}$ \\
\hline \multirow[t]{6}{*}{$45-64$} & Anders & Administrator & High & $\begin{array}{l}\text { Little knowledge, online } \\
\text { search for information }\end{array}$ \\
\hline & Bertil & Journalist & High & $\begin{array}{l}\text { Medium knowledge, online } \\
\text { search for information and } \\
\text { online communication }\end{array}$ \\
\hline & Carl & Pastor & Medium & $\begin{array}{l}\text { No knowledge of e-health } \\
\text { and no previous use }\end{array}$ \\
\hline & Ella & Administrator & High & $\begin{array}{l}\text { Some knowledge, online } \\
\text { search for information }\end{array}$ \\
\hline & Gunilla & Financial administrator & High & $\begin{array}{l}\text { Some knowledge, online } \\
\text { search for information on } \\
\text { medication }\end{array}$ \\
\hline & Frida & $\begin{array}{l}\text { Administrator of a } \\
\text { family company }\end{array}$ & Medium & $\begin{array}{l}\text { Some knowledge, no } \\
\text { previous use }\end{array}$ \\
\hline \multirow[t]{6}{*}{$65+$} & Hans & Retired Manager & Limited & $\begin{array}{l}\text { Little knowledge, no } \\
\text { previous use }\end{array}$ \\
\hline & Ingmar & $\begin{array}{l}\text { Retired Professor } \\
\text { and Consultant }\end{array}$ & High & $\begin{array}{l}\text { Good knowledge, quite } \\
\text { extensive previous use } \\
\text { mainly as source of } \\
\text { information }\end{array}$ \\
\hline & Johan & University Professor & Medium & $\begin{array}{l}\text { Some knowledge, online } \\
\text { search for information }\end{array}$ \\
\hline & Karolin & Economist & High & $\begin{array}{l}\text { Some knowledge, no } \\
\text { previous use }\end{array}$ \\
\hline & Lena & $\begin{array}{l}\text { Employment office } \\
\text { counselor }\end{array}$ & High & $\begin{array}{l}\text { Some knowledge, online } \\
\text { information search }\end{array}$ \\
\hline & Miriam & Retired English teacher & None & $\begin{array}{l}\text { No knowledge of e-health } \\
\text { and no previous use }\end{array}$ \\
\hline
\end{tabular}


Three of the members of the older age group, one male and two females, are quite experienced Internet users. Johan, a university professor, described himself as having a medium amount of experience - he uses it in his job. Hans, a retired manager, never used the Internet while working, but has some idea of what it can do for him. Since retiring, he has used it for simple tasks, such as reading newspapers online. Miriam, however, never used the Internet or computers and considered herself very inexperienced. When it came to the awareness and knowledge of e-health services, Ingmar appeared the most knowledgeable about the kind of health care information that is available online. He had visited several health sites and services before and even communicated with his doctor online. Like the younger members though, most of the others were aware of the Internet as a health information medium and searched online every now and then.

\section{Attitude toward using e-health}

None of the participants in the study were aware of the three e-health services investigated, even though all were residents of the county of Norrbotten and some of them even had visited the county council's website. The services were thus described to them. In general, they had a very positive attitude toward the use of e-health services. They all liked the idea of health care being provided through the Internet. The online health guide was perceived as an especially good complement to traditional health care, as Ingmar, one of the members in the older age group, put it, "The services are a good idea and definitely an answer to health needs in the near future; of course, when it comes to deeper questions you want to have a doctor to talk to."

All three services were perceived as a good idea; yet all participants expressed more reluctance about the ask-the-doctor online service than about the online health guides and e-prescriptions.

\section{Usefulness of e-health}

Apart from Carl, whose wife was a nurse, all of the other respondents found the online health guide and the ability to renew prescriptions online to be very useful. Carl stated that an online health guide and e-prescriptions would be useful for someone who was not as fortunate as he was to have a professional nurse at home. He simply had no need for such a service. The services were considered useful when looking for general information in situations that are not urgent or serious and thus consider them a great complement.
Even though the ask-the-doctor service can offer the same type of information as the health guide, yet more personalized, the respondents were generally more resistant to call the service useful. Like Carl, Miriam thought that the ask-the-doctor function, even though a good idea, was not especially useful. After further discussion this belief was found to stem mainly from the fact that even though a response is often received within a day or two the service can only guarantee to respond within a week. Most of the respondents considered this far too long to wait.

In summary, the characteristics of the three services that were acknowledged most and make them useful for the individuals are: time savings, convenience, and cost savings. Convenience was the most important, particularly since seeing a doctor or going to the pharmacist in Sweden is associated with having to stand in line or wait for an appointment for a long time. Online services help to make processes more efficient and avoid bottlenecks.

\section{Ease of use}

"If what I am looking for is easy to find, I will use it [the service]" -Anders.

In order to assess ease of use of the services and usability, all three services were demonstrated to the respondents and they had a chance to click through and explore the site. Ease of use was not an issue simply because none of the individuals thought the services were difficult to use. Only Hans, the retired manager, pointed out that since he was not used to the computer, he would have to learn. At the same time, he added that if he needed specific health information or if he had to renew a prescription (which he did not at the time of the interview) he did not think it would be difficult to learn how to do so using the online services.

When discussing the services with the interviewees, ease of use was considered very important. The interviewees with the least Internet experience were worried that they would have difficulty using the services. Yet once they visited the website and the click-through series, even those who had initially been hesitant reported being confident in their ability to use the services.

\section{Intention to use e-health in the future}

"... I believe it looks very interesting, not to say, tempting" Miriam.

Respondents gave, for the most part, affirmative answers towards their intention to use the online health guide and e-prescriptions. Three were not convinced that they would use such services in the future. Carl stated that he simply 
did not need "additional health information" or renewing prescriptions since his wife was a nurse, and he considers himself and his family rather healthy. Hans does not intend to use any of the three services. Like Carl, Hans does not have any need for additional health information and is "not interested." He also considers himself healthy and only contacts his doctor once a year for his check-up. However, Hans emphasized that this can change, saying, "If I would become sick or would suffer from some sort of disease, I might use the Internet as a source of information."

Lena, one of the older women, doubted whether she would use the services. She claimed that she would rather have more information about the services before deciding to trust them. A follow-up conversation revealed that Lena had visited and used the lexicon after being introduced to it during the interview; she was then excited about continuing to use it.

In contrast to the other services under examination here, the intention to use the ask-the-doctor service varied the most. Again, it became clear that even though it offers more personalized service than the health guide, the interviewees doubted its usefulness and whether they would to use it. After more discussion with them, it seemed that the problem with the ask-the-doctor function is that it does not really offer any advantage over the health guide, other than you get a personal response from a doctor. However, "if you want a personal response from a doctor you might as well just want to go and visit one."

\section{Concerns}

One of the biggest concerns among the interviewees was the risk of misunderstanding. This is seen from two perspectives: misunderstanding the information that is obtained from the online health guide even through the ask-the-doctor service (patient's side), and having the doctor misunderstand what the illness may be (as a result of not being able to describe it thoroughly in the case of the ask-the-doctor service). Personal contact usually would allow further explanations, follow-up questions, and dialog between patient and doctor if something is not clear. The lack of physical presence makes it difficult to have an opinion about the person who is providing the information and the possibility to show where it hurts.

Privacy and security issues were brought up, particularly with e-prescriptions, yet none of the interviewees had concerns in this regard. After further discussion, it became clear that this is because the Swedes trust the government, the county councils, and the public health care providers that offer the services investigated here. During the interviews, the issue of trust in the provider and the information was brought up constantly by the respondents.

\section{Discussion}

E-health was in general, perceived as a good idea and attitudes towards it were mostly positive. Still, the participants showed a different level of interest in each particular service depending on the situation.

Looking into the TAM variables, as was expected, usefulness was perceived important. Ease of use, proposed as the second key determinant of technology acceptance in TAM, did not seem to be an issue in this context. The three services investigated were perceived as being easy to use. This might reflect the suggested weight of experience with the system or service on the impact of ease of use on attitude, as suggested by Venkatesh. ${ }^{28}$

\section{So, what hinders e-health adoption?}

In the general literature on e-health, the issue of access has gained substantial attention. A lack of access for some part of the population can lead to a so-called digital divide, meaning that some part of the population is excluded from the development toward the e-society. ${ }^{11,18,39}$ Access is not included in original innovation diffusion and technology acceptance literature, simply because this stream of research is grounded in an organizational context, where employees are given access. Yet Sweden has one of the highest rates of Internet coverage in Europe ${ }^{40}$ and also all of the participants in this study, even those in the older age group, had easy access to the Internet.

One of the most surprising findings was that none of the individuals included in this investigation, even though they all had different backgrounds and a varying level of Internet use and experience, was aware of the three e-health services offered by their local county council. It became evident during the interviews that they had a positive attitude towards use of the e-health services and found them to be useful. Simple lack of awareness was the main reason why the interviewees had not previously made use of the services. Citizens need to be better informed of the resources that are available to them. Otherwise, they will continue to turn to the health care center each time a health question arises and the investment in Internet services will be wasted.

Another impediment to the use of e-health services is what we call resistance to change. Rogers' ${ }^{41}$ Theory of Innovation Diffusion (IDT) proposes a concept called compatibility, which we believe explains this phenomenon. Simply put, people prefer to do things the way they have always done them. Whether we adopt an innovation thus 
depends on the extent to which this innovation is compatible with our usual behavior, way of doing things, and lifestyle. However, as Miriam stated, "that is there to be conquered."

We believe that the only way to make people try out new services is to offer some kind of additional value. E-health services have the potential to offer this additional value, yet as emphasized earlier, people have to be made aware of their existence and benefits.

"All of those services are useful; you just need to get used to new ways" -Ella.

One last impediment to use during this research is the way in which the specific NLL services were set up at the time of the interviews. Long waiting times to receive answers to the questions in the ask-the-doctor service and the fact that the communication cannot be established with the person's own doctor were mentioned as drawbacks to the services. Miriam stated, “....you don't want to have to tell your whole life story to a new doctor... to be able to answer they must know a lot about you."

\section{Conclusion}

The Internet has the potential to improve the delivery of health care service, make it faster, more efficient and cost effective for providers. At the same time, it can empower citizens to take better care of themselves. This paper took a qualitative approach to examine determinants of acceptance of three e-health services that are offered by county councils in Sweden. In-depth interviews were conducted, guided by a "robust, powerful and parsimonious model for predicting user acceptance" 28 from IS, the TAM. By contributing to the knowledge of citizens' perspectives of and concerns about the services that are provided today, developers and providers of e-health will be better prepared to meet the real needs of their target population in the future.

One of the findings which we believe has the most important implications for health care providers is that none of the interviewees had ever heard of the three different e-health services. Thus, we thus want to highlight that the first step to the acceptance and adoption of online health care services is ensuring that citizens know of their existence and benefits.

TAM suggests, and this study confirms, that PU is one of the main determinants of an individual's acceptance of a technology. The findings show that all of the interviewees to a lesser or greater extent find online health guides and e-prescriptions useful. Major benefits that they acknowledged are convenience, and savings of time and money. In general, the interviewees regard the e-health services as a very good complement to existing health care services. Ease of use, as mentioned before, did not seem to be a concern in this context. This could be reflecting the influence of the experience variable proposed by Venkatesh. ${ }^{28}$

When further exploring attitudes toward the use of e-health services and intention to use any of those in the future another factor appeared to be key, the individual's resistance to change. We are comfortable with doing things we way we are used to. A concept related to this that has been proposed in IS research is the concept of compatibility, how an innovation fits into our lifestyle. Based on the findings of this study, we believe that this concept has strong implications for the acceptance of e-health and suggest its inclusion in future research of e-health acceptance.

Furthermore, trust in the provider of the service is crucial for people's willingness to make use of it. In this case, the county councils provide the services; in Sweden, these councils are highly trusted and considered reliable. However, in another context, where the provider is a private company or organization, gaining trust can be pivotal. Online health care has its disadvantages, such as the risk of misunderstanding information, obtaining inaccurate information, or technical problems with security and privacy. Trust in the service provider that can overcome those barriers and reduce risk. Thus, we strongly recommend future researchers to include the concept of trust in their investigations.

One last thing that we would like to point out is that access should be a crucial issue in addressing consumers' intention to use in countries with less coverage and a weaker infrastructure than Sweden's.

\section{Limitations and future research}

The limitations of the study should be highlighted in order to guide future research. First, the study was conducted in northern Sweden. Qualitative studies of adults in other parts of the country would enrich the findings of this study and provide a better understanding for providers and developers in Sweden. In addition, studies that go beyond the Swedish borders would bring a different perspective and take into consideration people who live under different socio-political conditions. Another aspect of the sample is that most of these participants were highly educated; results may vary when other groups are included. Additional demographic variables and other aspects of usage behavior could be explored.

Only a small fraction of the e-health service spectrum was addressed in this study. Other services might be suited to users with other needs, who are in different situations, and might raise a whole new set of concerns. Studying other e-health services is therefore recommended. 
This research placed depth of insight above generalizing; it is qualitative and discovery-oriented, exploratory in nature. Large-scale quantitative studies dealing with e-health provision from a citizen's perspective might be able to generalize findings for the benefit of larger populations and help secure success of e-health investments.

Finally, this study is limited to the examination of three e-health services: an online health guide, an ask-the-doctor online service, and e-prescriptions. These three services are most common in Sweden and thus most suitable to examine in this study. Yet there are others that could be investigated to further contribute to our knowledge of e-health acceptance. Studies that go beyond the Swedish borders and examine other populations would bring a different perspective and address people that live under different socio-political conditions.

\section{Disclosure}

The authors report no conflicts of interest in this work.

\section{References}

1. Karlsson M, Mayhew L, Plumb R, Rickayzen B. An International Comparison of Long-Term Care Arrangements. 2004 [cited 2004 Apr 26]; http://www.cass.city.ac.uk/media/stories/resources/Full_report_-_LTC. pdf. Last accessed October 27, 2006.

2. Tarre K. Applied ICT in the Health care Industry in Sweden. Invest in Sweden Agency's IT Sweden Project; 2003.

3. Cabrera M, Burgelman JC, Boden M, da Costa O, Rodriguez C. e-Health in 2010: Realizing a Knowledge-based Approach to Health care in the EU - Challenges for the Ambient Care System. Report on e-Health related activities by IPTS, European Commission, Directorate-General, Joint Research Centre; 2004.

4. Saritas O, Keenan M. Broken promises and/or techno dreams? The future of health and social services in Europe. Foresight. 2004;6(5):281-191.

5. Kun LG. Telehealth and the global health network in the 21 st century. From homecare to public health informatics. Comput Meth Programs Biomed. 2001;64:155-167.

6. Koch S. ICT-based Home Health care - Research State of the Art. Department of Medical Science, Uppsala University (on behalf of VINNOVA); 2004.

7. Pagliari C, Sloan D, Gregor P, et al. What is e-health (4): a scoping exercise to map the field. $J$ Med Internet Res. 2005;7(1):e9.

8. Commission of the European Communities. E-Health-Making Health care Better for European Citizens: An Action Plan for a European E-Health Area. Communication from the Commission to the Council: the European Parliament, the European Economic and Social Committee, and the Committee of the Regions. [SEC(2004)539].

9. Jai Ganesh AU. E-health - drivers, applications, challenges ahead, and strategies: a conceptual framework. Ind J Med Inform. 2004;1:39-47.

10. González ME, Quesada G, Urrutia I, Gavidia JV. Conceptual design of an e-health strategy for the Spanish health care system. Int J Health Care Quality Assurance. 2006;19(2):146-157.

11. Duffy M, Wimbush E, Reece J, Eadie D. Net profits? Web site development and health improvement. Health Education. 2003;103(5): 278-285.

12. Chin R. The Internet: another facet to the paradigm shift in health care. Singapore Med J. 2000;41(9):426-429.
13. Mullner RM. The Internet and health care: opportunities and challenges. J Med Sys. 2002; 26(6):491-3.

14. Kassirer JP. Patients, physicians, and the Internet. Health Affairs. 2000;19(6):115-123

15. Leonard KJ. Critical success factors relating to health care's adoption of new technology: a guide to increasing the likelihood of successful implementation. Electronic Health care. 2004;2(4):72-81.

16. Parente ST. Beyond the hype: a taxonomy of e-health business models. Health Affairs. 2000;19(6):89-102.

17. Orr S, Sohal AS, Gray K, Harbrow J, Harrison D, Mennen A. The impact of information technology on a section of the Australian health care industry. Benchmark Int J. 2001;8(2):108-119.

18. Kerwin KE. The role of the Internet in improving health care quality. J Healthc Manag. 2002;47(4):225-236.

19. Chismar WG, Wiley-Patton S. Does the Extended Technology Acceptance Model Apply to Physicians. Proceedings of the 36th Hawaii International Conference on System Sciences (HICSS'03); 2003 Jan 6-9; Big Island, Hawaii, USA. Washington, DC: IEEE Computer Society; 2003.

20. Fonkych K, Taylor R. The State and Pattern of Health Information Technology Adoption. RAND Corporation Monograph series; 1998.

21. Wickramasinghe NS, Faklalla AMA. A framework for assessing e-health preparedness. Int J Electron Healthc. 2005;1(3):316-334.

22. Wilson EV, Lankton NK. Modeling patient's acceptance of provider-delivered e-health. J Am Med Inform Assoc. 2004;11(4):241-248.

23. Ross J, Chapman C, Murray C, Stevenson M, Natin D, Rogstad K. How much interest is the Internet to patients? Sex. Transm. Inf. 2000;76:393-4.

24. Davis FD. A Technology Acceptance Model for Empirical Testing New End-User Information Systems: Theory and Results. Doctoral Dissertation: Sloan School of Management, Massachusetts Institute of Technology; 1986.

25. Adams DA, Nelson RR, Todd PA. Perceived usefulness, ease of use, and usage of information technology: a replication. MIS Quarterly. 1992;16(2):227-247.

26. Davis FD, Bagozzi R, Warshaw P. User acceptance of computer technology: a comparison of two theoretical models. Management Science. 1989;35(8):982-1003.

27. Chau PYK, Hu PJH. Investigating health care professionals' decision to accept telemedicine technology: an empirical test of competing theories. Information and Management. 2002;39:297-311.

28. Venkatesh V, Davis FD. A theoretical extension of the technology acceptance model: four longitudinal field studies. Management Science. 2000;24(2):186-204.

29. Fishbein M, Ajzen I. Belief, Attitude, Intention and Behavior: An Introduction to Theory and Research. Reading, MA: Addison-Wesley; 1975.

30. Davis FD. Perceived usefulness, perceived ease of use, and user acceptance of information technology. MIS Quarterly. 1989;13(3):319-340.

31. Venkatesh V. Creation of favorable user perceptions: exploring the role of intrinsic motivation. MIS Quarterly. 1999;23(2):239-260.

32. Hu PJH, Chau PYK, Sheng ORL. Adoption of telemedicine technology by health care organizations: an exploratory study. J Org Comp Electronic Commerce. 2002;12(3):197-221.

33. An JY. Correlates and Predictors of Consumer's Health Information and Services Usage Behavior on the Internet: A Structural Equation Modelling Approach. Doctoral Dissertation: Steinhardt School of Education, New York University; 2005.

34. Hu PJH, Chau PYK, Sheng ORL, Tam KY. Examining the technology acceptance model using physician acceptance of telemedicine technology. J Manag Inform Syst. 1999;16(2):91-112.

35. Denzin NK, Lincoln YS. Handbook of Qualitative Research. 2nd ed. Thousand Oaks, CA: Sage Publications; 2000.

36. Yin RK. Case Study Research - Design and Methods. 2nd ed. Applied Social Research Methods Series Vol. 5. Thousand Oaks, CA: Sage Publications; 1994. 
37. McCracken G. The Long Interview. Qualitative Research Methods Series Vol. 13. Thousand Oaks: Sage Publications; 1988.

38. Miles MB, Huberman AM. Qualitative Data Analysis. 2nd ed. Thousand Oaks, CA: Sage Publications; 1994.

39. Powell JA, Darvell M, Gray JAM. The doctor, the patient, and the world-wide-web: how the Internet is changing health care. $J R S O c$ Med. 2003;96:74-76.
40. Statistics Sweden. Privatpersoners Användning av Datorer och Internet 2005, Statistiska Centralbyrån; 2005.

41. Rogers, EM. Diffusion of Innovations. 4th ed. New York, NY: The Free Press; 1995.

\section{Publish your work in this journal}

The Journal of Multidisciplinary Healthcare is an international, peerreviewed open-access journal that aims to represent and publish research in healthcare areas delivered by practitioners of different disciplines. This includes studies and reviews conducted by multidisciplinary teams as well as research which evaluates the results or conduct of such teams or healthcare processes in general. The journal covers a wide range of areas and welcomes submission from practitioners at all levels, from all over the world. The manuscript management system is completely online and includes a very quick and fair peer-review system. Visit http://www.dovepress.com/testimonials.php to read real quotes from published authors.

Submit your manuscript here: http://www.dovepress.com/journal-of-multidisciplinary-healthcare-journal 